\title{
DOE/SF/18852-. T77 \\ CASSINI RTG ACCEPTANCE TEST RESULTS AND RTG PERFORMANCE ON GALILEO AND ULYSSES
}

\author{
C. Edward Kelly \\ Lockheed Martin Corporation \\ P.O. Box 8555, 29B41-KB \\ Philadelphia, Pennsylvanla 19101 \\ Paul M. Klee \\ Lockheed Martin Córporation \\ P.O. Box 8555, 29841-KB \\ Philadelphla, Pennsylvania 19101
}

\begin{abstract}
Flight acceptance testing has been completed for the RTGs to be used on the Cassini spacecraft which is scheduled for an October 6, 1997 lounch to Saturn. The acceptance test progran includes vibration tests, magnetiv field measurements, mass properties (weight and c.g.) and thermal vacuum test. This paper presents the thermal vacuum test results. Thro RTGs we to be used, F-2, F-6, and F-7. F-5 is the back-up RTG, as it was for the Galileo and Ulysses missions launched in 1989 and 1990, respectively. RTG performance measured during the thermal vacuum tests carried oul at the Mound Laboratory facility met all specification requirements. Beginning of mission (BOM) and end of mission (EOM) power predictions have been made based on these tests results. BOM power is predicted to be 888 wats compared to the minimum requirenient of 826 watts. Degradation models predict the EOM power after 16 years is to be 640 walts compared to a minimum requirement of 596 watts. Results of small scale module tests are also shown. The modules contain couples from the qualification and flight production nuns. The tests have excceded 28,000 hours ( 3.2 years) and are conlinuing to provide increased confidence in the predicted long term performance of the Cessini RTGs. All test results indicate that the power requirements of the Cassini spacecraft will be met. BOM and EOM power margins of over five percent are predicted. Power output from telemetry for the two Galileo RTGs are shown from the 1989 launch to the recent Jupiter encounier. Comparisons of predicted, meastired and required perfomance are shown. Telemetry dath are also shown for the RTG on the Ulysses spacecraft which compleled its planned mission in 1995 and is now in the extended mission.
\end{abstract}

\section{INTRODUCTION}

The GPISS RTGs which were developed for the Galileo and Ulysares misesions bave bean previously described (Hemler, 1992). The units provide a nominul $300 \mathrm{~W}(0)$ with a hiel loading of 4,400 W(th), urilize silicon gemanium thermoelectric elements, a molybdenum multi-foil thermal insulation system, and an aluminum outer shell. They weigh $55.3 \mathrm{~kg}$, are 1 meter long and have a fin envelope of approximately 0.4 meters. The RTGs $(F-I, F-4)$ on Galileo have continued to exceed power requirements since the October 1989 launch Similarly, the Ulysses RTG (F-3) has met all nission power requirements since the October 1990 launch. Two new GPHS type RTGs (F-6 and F-7) have been built uncer the Cassini program. The third unit F-2, was built during the Galileo program but never fucled. The backup unit F-5 was built fucled and flight qualified under. the Galileo program. All of the units have undergone the Cassini flight acceptance program and are fully qualified for the scheduled October 6, 1997 launch to Saurn. Three RTGs will provide the power for the Cassini spacecrant and are required to provide a minimum of $826 \mathrm{~W}(\mathrm{c})$ ut the beginning of mission (BOM) and $596 \mathrm{~W}(\mathrm{c})$ afler sixteen (16) years (EOM). If the backup unit is used the BOM and BOM requirements are $799 \mathrm{W(e)}$ and 579 $W(e)$, respectively. Small sciale 18 couple module tests were used to demonstrate the initial and long tem electrical performance of the thernopile as discussed in the next section.

\section{CASSINI MODULE TEST PROGRAM}

The Cassini module test program consisted of three 18 couple modules. The purpose of the testing was to demonstrate that the unicouples made for the Cassini RTGs had the same performance characteristics as those used in the Galileo and Ulysses RTGs. Two modules were operated at higher than normal temperanure to obtain accelerated life data and the third was operated at nomal temperature. Tests results are shown in Figures 1 through 6 . Figures 1 and 2 show the power output and internal resistance trends for the Cassini modules 18-10 and $18-11$ operated at the accelerated temperanure of $1408 \mathrm{~K}$. Also shown for comparison are the trends for modules from the Galileo/Ulysses program. Similar plots are shown in Figures 3 and 4 for module 18-12 which was operated at the normal hot shoe temperature of $1308 \mathrm{~K}$ Thennopile electrical characteristics were found to bo in good agrement with previous units. Figures 5 and 6 provide the isolation resigtune trends berween the thermoeleetris circult and roil insulation system for modules operated at $1408 \mathrm{~K}$ and $1308 \mathrm{~K}$, respectively. These trends domonstrate that the silicon witride coating applied to the thermoelements to suppress sublimation and instre long life has been successfully reproduced in the Cassini unicouples. The comparative performance of the 
modules provides a high degree of confidence that the Cassini unicouples will provide the same electrieal performance as the Gailieo and Ulysses unicouples.

\section{CASSINI FULL SCALE CONVERTER TESTS}

\section{BTGF-5}

RTO F-S, which serves as the backsp RTG for the Cassini mission, completed acteptance testing in October 1995. This unit was fueled at the end of 1984 and also served as the bachup RTG for Galileo and Ulysses. Thermal vacuum power measured following vibration testing is shown in Table 1. Power outpur was 259 W(e) with a fuel loading of 4091 W(th). This is the power at the RTG connector pins. Three watts were added to the measured power to accolunt for the gas venting differences between the test configuration and a flight PRD (pressure relief device). Based on these test results the BOM (beginning of mission) power output is projected to be 251 We with a fuel load of 4029 W(th). EOM (end of mission) power calculated from degradation models is predictal to be 183 W(e). The spceification requirements are 249 W(c) BOM and 182 W(e) EOM This unit had the longest storage time ever experienced by an RTG. Internal resistance trends during storage clearly show the reversible nature of the dopant precipitation process. Storage condition is short circuit with hot and cold junction temperatures of $1003 \mathrm{~K}$ and $493 \mathrm{~K}$. Prior to launch the hot junction temperanure is raised to over $1173 \mathrm{~K}$ during an argon to xenon gas exchange process. During this process, previously precipitated dopant redissolves in certain temperature regions of the thermoelements. This results in a decrease in internal resistance when the unit is reamed to storage conditions as shown in Figure 7. The net result is that RIGs can be stored in the fueled state and exhibit very little power degradation other than that associated with fuel decay. In fact, F-5 with 10 years of storage between themal vacuum tests degraded by only two percent when normalized to a constant fuel loading.

TABLE 1. MEASURED AND PROJECTED POWER OUTPUT

\begin{tabular}{|l|c|c|c|c|}
\hline & $\begin{array}{c}\text { Measured } \\
\text { Watts }\end{array}$ & $\begin{array}{c}\text { BOM } \\
\text { Fuel }\end{array}$ & $\begin{array}{c}\text { Projected } \\
\text { Watts }\end{array}$ & \\
\hline INII & & & BOM & EOM \\
F-2 & 301.2 & 4378 & 296 & 213 \\
F-6 & 299.2 & 4407 & 294 & 212 \\
F-7 & 302.6 & 4397 & 298 & 215 \\
F-5 & 261 & 4029 & 251 & 183 \\
& & & & \\
F-2, F-6. F-7 & & 13182 & 888 & 640 \\
F-2, F-5, F-6 & & 12814 & 841 & 608 \\
\hline
\end{tabular}

\section{ETGF-2}

F.2 was tested as an ETG in 1983 then put in storage at Mound Laboratory. RTG F-2 was fueled at Mound in Februnry 1996 and completed flight acceptance testing in September 1996. At the end of the thermal vacuum test the power output at the connector pins was $301.2 \mathrm{~W}(\mathrm{e})$ with a fuel loading of $4416 \mathrm{~W}(\mathrm{hh})$. Two watts were added to the ineasured power to account for venting difference between the test configuration and a flight PRD (pressure relief device). Table 1 summarizes measured and predicted performance. A BOM power output of $296 \mathrm{~W}(\mathrm{e})$ is predicted with a fuel loading of $4378 \mathrm{~W}(\mathrm{th})$. The specification requirement is $274 \mathrm{~W}(e)$. The large margin is due to the fact that the BOM fuel loading is higher than originally planned. A BOM fuel loading as low as $4,258 \mathrm{~W}($ th) had been anticipated based on fuel enrichment and packing density estimates available earlier in the program. EOM power is predicted to be $213 \mathrm{~W}(e)$ with a specification requirement of $198 \mathrm{~W}(\mathrm{e})$.

\section{BTG F.6}

F6 was fueled at Mound Laboratory in November 1996. Power output at the end of the thermal vaculum test was 299.2 W(e) at the RTG pins including a 2 W(e) GMV power correction. The fuel loading at that time was $4430 \mathrm{~W}(\mathrm{th})$. Table 1 summarizes meastred and predicted peformance. A BOM power of $294 \mathrm{~W}(\mathrm{e})$ is predicted with a fuel loading of $4407 \mathrm{~W}(\mathrm{~h})$. The specificetion requirement is $276 \mathrm{~W}(\mathrm{e})$. The BOM power prediction has been decreased by $2 W(e)$ as an allowance for power loss due to air infusion. Gas top data analysis showed higher than normal nitrogen levels. There will be some oxidation of moly foil which will increase heat losses slightly. EOM power is predicted to be 212 W(e) with a requirement of 199 W(e).

\section{BTG E-T.}

F-7 was fueled in September 1996. Thermal inventory at the time of the thermal vacuum test in November 1996 was $\mathbf{4 4 2 8}$ W(th). Power output at the end of thernal vacurm testing was $302.6 \mathrm{~W}(\mathrm{e})$ at the RTG pins including a $2 \mathrm{~W}(\mathrm{e}) \mathrm{GMV}$ power correction. Measured and predicted performance are given in Table 1. $298 \mathrm{~W}(\mathrm{e})$ is predicted for B.O.M compared to the requirement of $276 \mathrm{~W}(\mathrm{e})$. EOM power is predicted to be 215 W(e).

The total Cassini spacecraft BOM power specification requirement is 799 We using RTGs $F-2, F-5$, and F-6. Predicted power based on thermal vacuum meisurements is 841 $W(e)$ for a 5 percent margin. Similarly, for RTGs $F-2, F-6$, and $F$ 7 the specification is 826 W(e) with a predicted power of 888 We for a 7 percent margin. EOM specification and projections are 579 We and 608 We, respectively, for RTGs F-2, S, and 6 and 596 We and 640 We, respectively, for RTGs $F-2,6$ and 7. EOM inargins are calculated to be 5 and 7 percent.

\section{GALILEO RTG performance}

The Galileo spacecraft was launched in October 1989 on a six year joumey to explore Jupiter and its surrounding moons. It arrived on December 7, 1995 after a circuitous route that involved Earth flybys in 1990 and 1992 . It is interesting to note that the smaller Voyager spacecraft on a direct trajectory flew by Jupiter eighteen months after launch. Telemetry dats have been provided by JPL during the Galileo nission and the power profile is shown in Figure 8 up to September 1996 . The power is calculated at the spacecraft bus by multiplying the mensured current from each RTG by the constant bus voltage. The accuracy of the measured current is estimated to be $\pm 1.2 \%$ which corresponds to \pm 3 We for the power from each RTG. Initial power was reported as 577 We which was 9 We above the specification requirement. R/TG power output his continued to exceed spacecraft required power throughout the mission. 


\section{ULYSSES RTG PERFoRMANCE}

The Ulysses spacecraft was launched in October 1990 with a single RTG, F-3. Its trajectory led it to the planet Jupiter, where in Februny 1992, it received a gravitational assist that sent it out of the plune of the Earth's orbit and eventually over the poles of the sun. It passed over the south pole in October 1994 and the north pole in 1995. Ulysses completed its original 4.7 year mission in August 1995 and is now in an extended mission of a second polar orbit. The power estimates for F-3 are shown in Figure 9. Unlike Galileo there is no direct messurement of RTG power output. RTG power output is estimated from an algorithm which considers (1) the main bus current (2) an internal power dump currenth and (3) nominal power consumption palues for ten spacecraft components if they are operating at the time. Initial telemetry power was reported to be $289 \mathrm{~W}(e)$ at the RTG connector which exceeded the specification requirenent of 277 W(e). The prelaunch prediction of BOM power was in the range 282 to 287 W(e). The RTG continued to mest all spacecraft power requirements throughout the 42,000 hour (4.8 year) mission. The EOM power requirement was $245 \mathrm{~W}(\mathrm{e})$. JPI has reported that during the periods leading up to an following perihelion in March 1995, there were several spacecrat power reconfigurations in response to the large changes in solar heating as the spacecraftSun distance decreased and then increased. Since the algorithm used to estimate power is configuration dependent, these reconfigurations bave clearly introduced artifacts into the dato set.

\section{CONCLUSIONS}

Test results indicate that the BOM and EOM power requirements for the Cassini spacecraft will be met by three RTOs with a power margin of five percent. Telemetry data from the Galileo and Ulysses spacecraft show that all nussion power requirements have been niet.

\section{ACKNOWLEDGMENTS}

The authors acknowledge with thanks the many contributions made by the staffs of the Lockheed Martin Corporation, EG\&G Mound Applied Technologies, Savannah River Plant and Laboratory, Los Alamos National Laboratory, Oak Ridge National Laboratory, Sandia National Laboratories, Ames Laboratory, Orbital Sciences, NUS Corporation, the Applied Physics Laboratory, Westinghouse Hanford Company, and Battelle Columbus Laboratories in the design, analysis, fabrication and testing of the GPHS-RTGs, and their components.

Acknowledgments with thanks is also given to $R$ Campbell of JPL who provided the flight data for Galileo and Ulysses and also valunble consultation regarding interpretation of the data.

\section{REFERENCES}

Hemier, R J. et al, 1992, "Flight Pefformance of Galileo and Ulysses RTGs," Proceeding of the Ninth Symposium on Space Nuclear Power Systems, Albuquerque, New Mexico, 12-16 January 1992, American Institute of Physics Conference Proceedings 246, 1:171-176. 


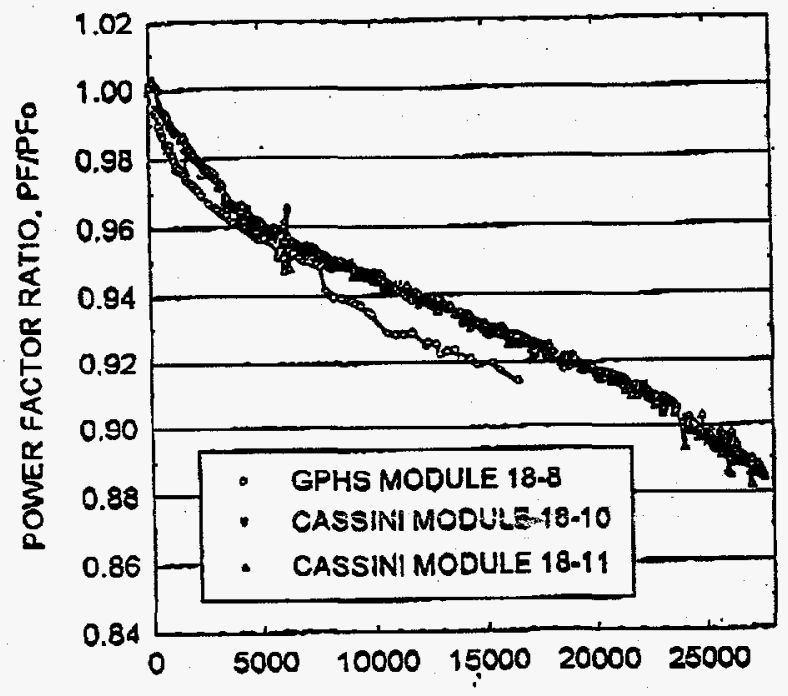

TIME AT TEMPERATURE, HOURS

FIGURE 1. 18 COUPLE MODULE POWER FACTOR VERSUS TTME (1408 K OPERATION)

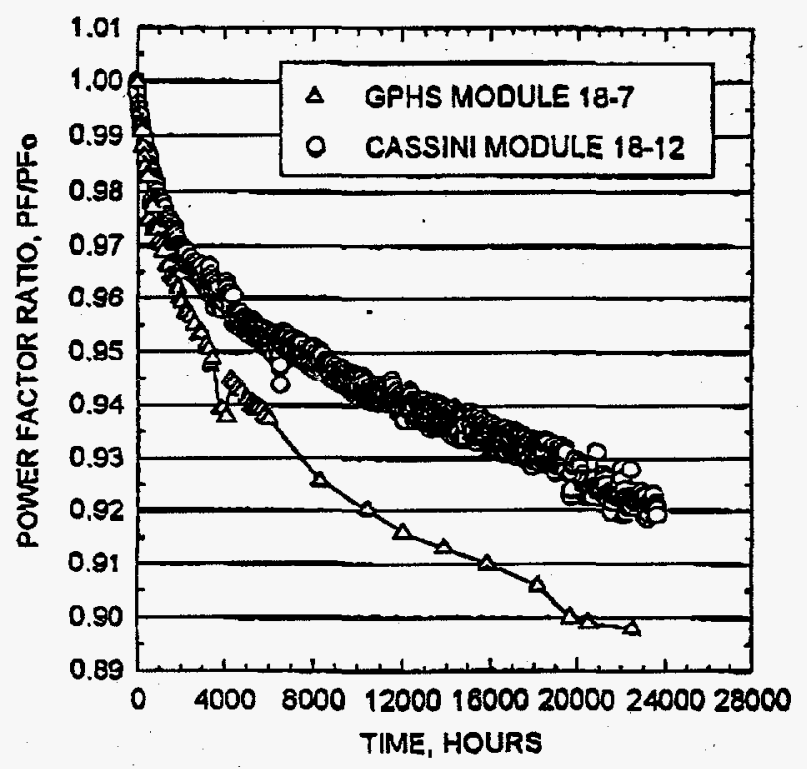

FIGURE 3. 18 COUPLE MODULE POWER FACTOR RATIO VERSUS TIME (1308 K OPERATION)

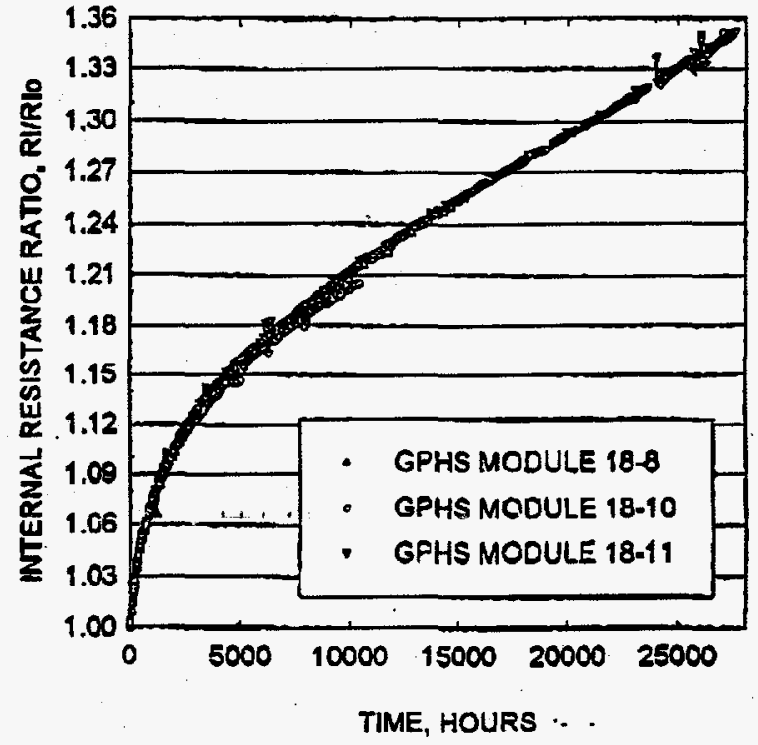

FIGURE 2. 18 COUPLE MODULE INTERNAL RESISTANCE RATIO VERSUS TIME (1408K OPERATION)

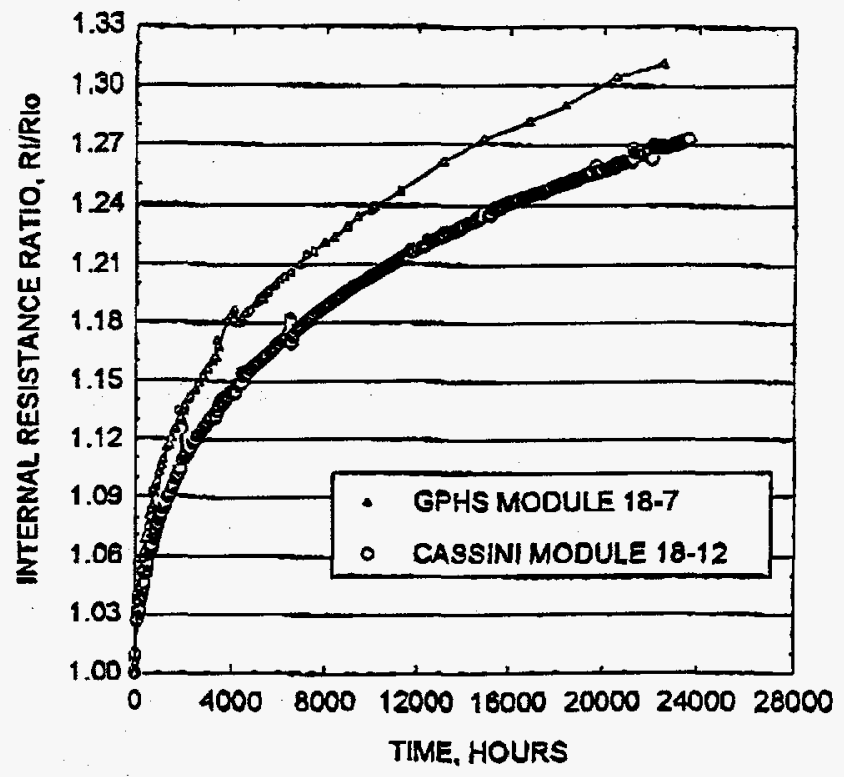

FIGURE 4. 18 COUPLE MODULE INTERNAL RESISTANCE RATIO VERSUS TIME (1308 K OPERATION) 


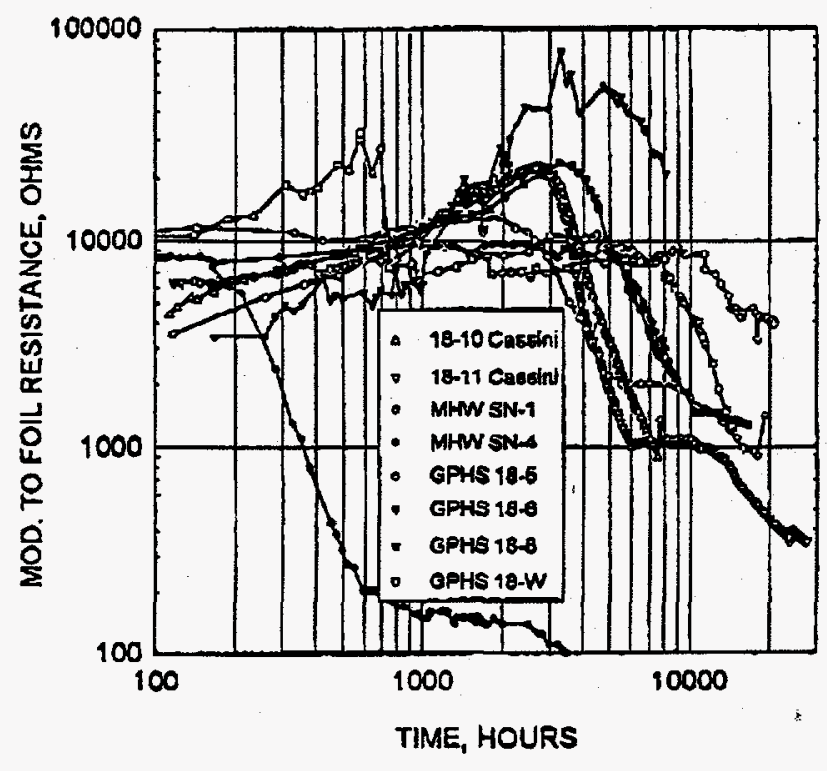

FIGURE 5. ISOLATION RESISTANCE VEASUS TIME (1408 K OPERATION)

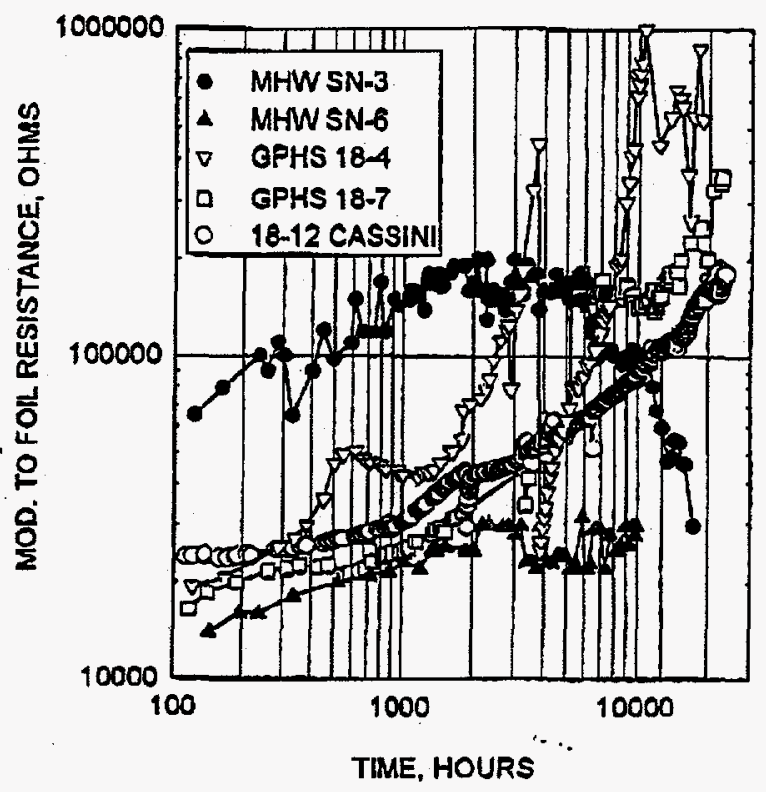

FIGURE 6. ISOLATION RESISTANCE VEASUS TIME (1308 K OPERATIONS)

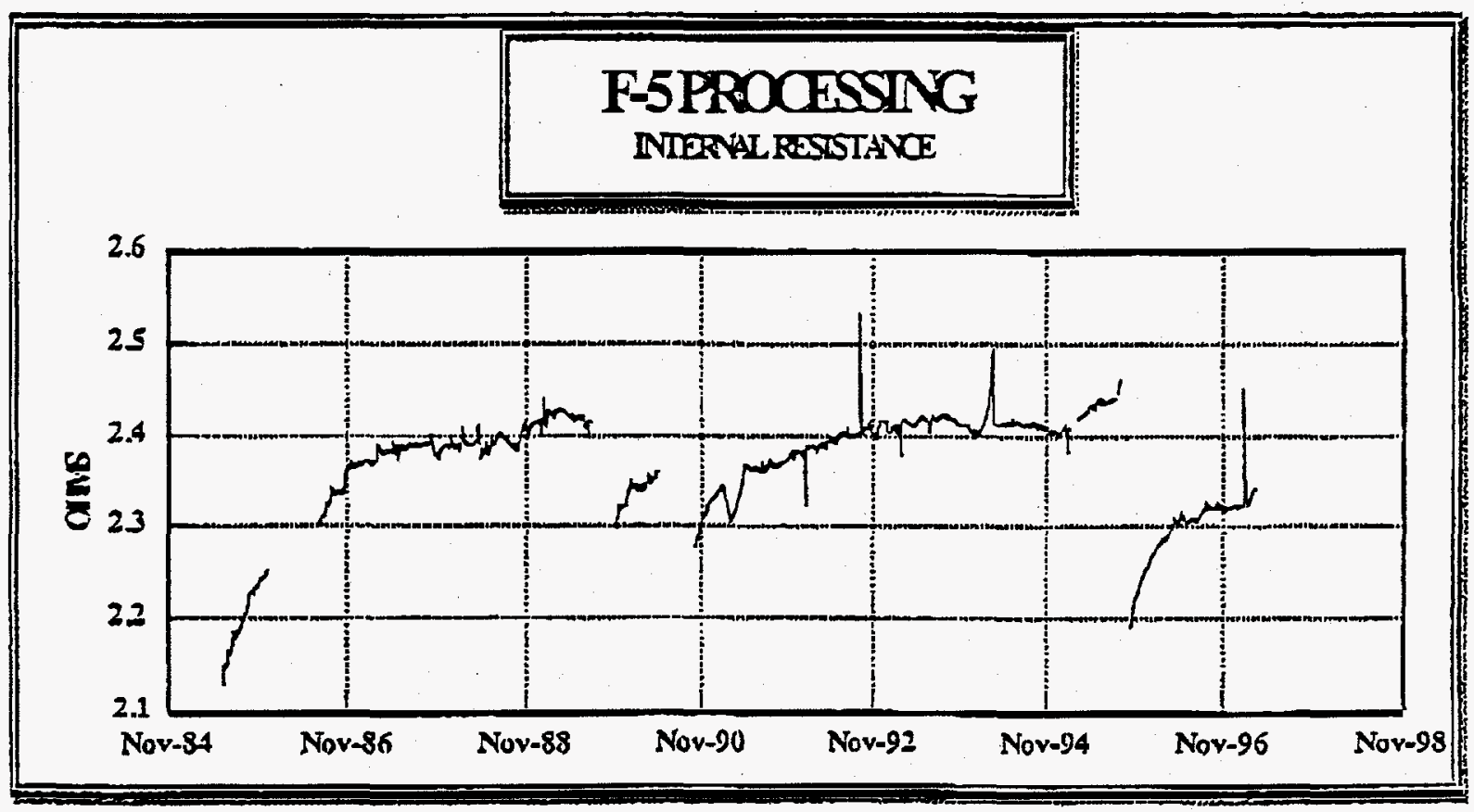

FIGURE 7. F-5 INTERNAL RESISTANCE TRENDS 


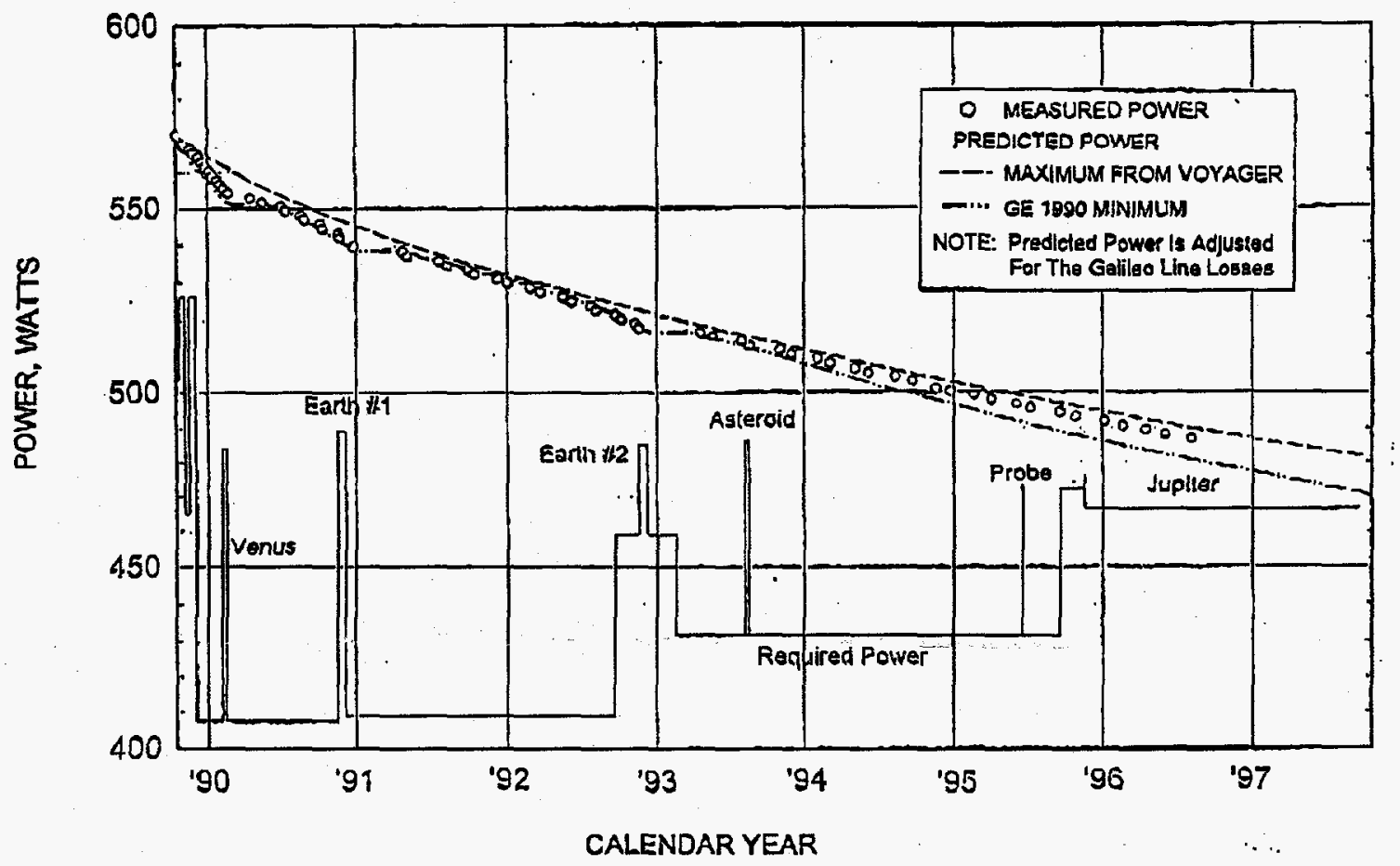

FIGURE 8. GALILEO SPACECRAFT RTG POWER VERSUS TIME (LAUNCH OCTOBER 18, 1989)

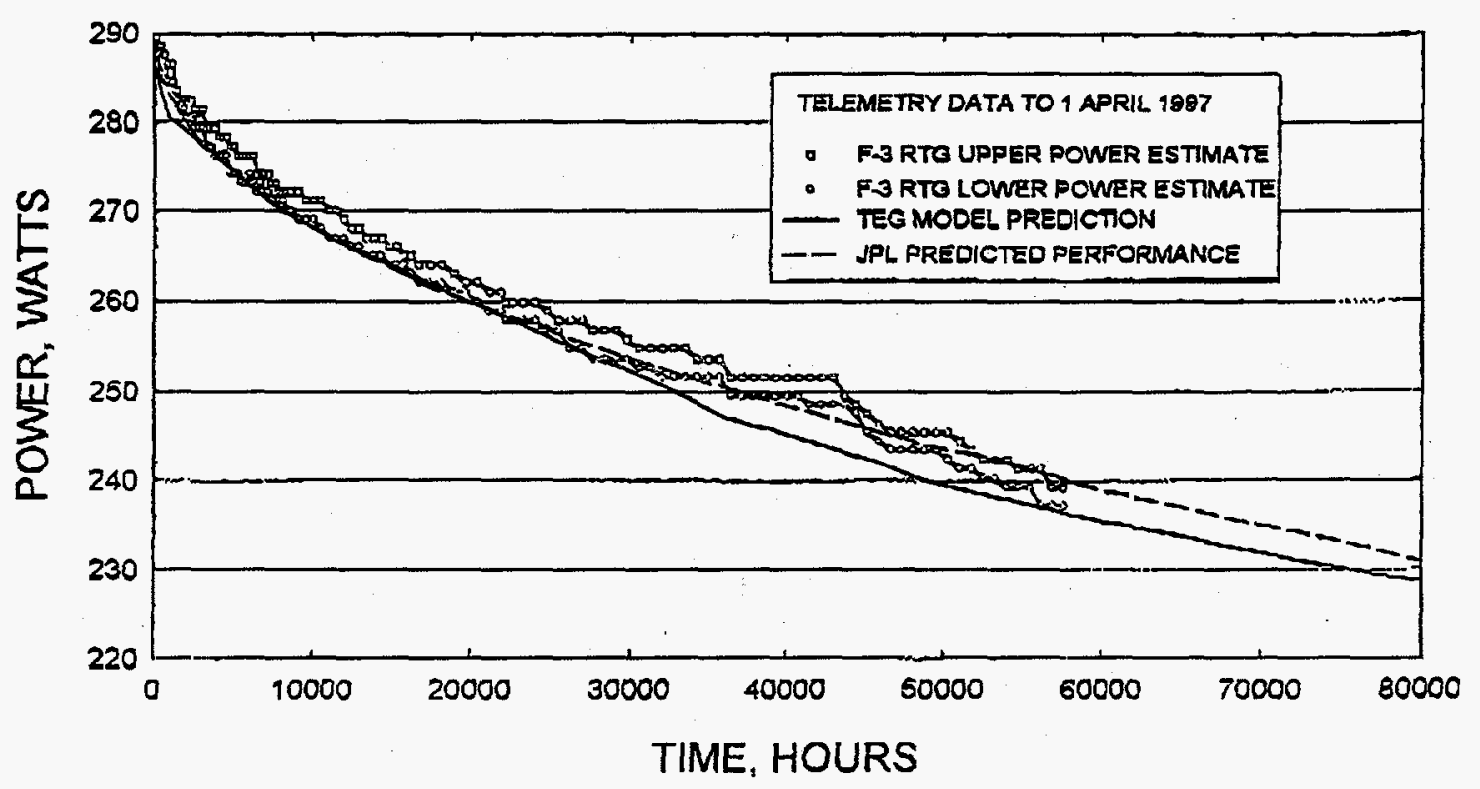

FIGURE 9. ULYSSES SPACECRAFT RTG POWER (LAUNCH OCTOBER 6,1990) 


\section{DISCLAMMER}

Portions of this document may be illegible in electronic image products. Images are produced from the best available original document. 